Fungus gardens of the leafcutter ant Atta colombica function as egg nurseries for the snake Leptodeira annulata.

Baer, Boris; Den Boer, Susanne Petronella A; Kronauer, Daniel; Nash, David Richard;

Boomsma, Jacobus Jan

Published in:

Insectes Sociaux

DOI:

10.1007/s00040-009-0026-0

Publication date:

2009

Document version

Publisher's PDF, also known as Version of record

Citation for published version (APA):

Baer, B., Den Boer, S. P. A., Kronauer, D., Nash, D. R., \& Boomsma, J. J. (2009). Fungus gardens of the leafcutter ant Atta colombica function as egg nurseries for the snake Leptodeira annulata. Insectes Sociaux, 56(3), 289-291. https://doi.org/10.1007/s00040-009-0026-0 


\title{
Fungus gardens of the leafcutter ant Atta colombica function as egg nurseries for the snake Leptodeira annulata
}

\author{
B. Baer · S. P. A. den Boer - D. J. C. Kronauer · \\ D. R. Nash · J. J. Boomsma
}

Received: 6 March 2009/Revised: 1 May 2009/Accepted: 8 May 2009/Published online: 13 June 2009

(c) Birkhäuser Verlag, Basel/Switzerland 2009

\begin{abstract}
Attine ants are well known for their mutualistic symbiosis with fungus gardens, but many other symbionts and commensals have been described. Here, we report the discovery of two clusters of large snake eggs in neighboring fungus gardens of a mature Atta colombica colony. The eggs were completely embedded within the fungus garden and were ignored by the host ants, even when we placed them into another, freshly excavated fungus garden of the same colony. All five eggs contained embryos and two snakes eventually hatched, which we identified as being banded cat eyed snakes Leptodeira annulata L. Ant fungus gardens are likely to provide ideal climatic conditions for developing snake eggs and almost complete protection from egg predation. Our observations therefore
\end{abstract}

Electronic supplementary material The online version of this article (doi:10.1007/s00040-009-0026-0) contains supplementary material, which is available to authorized users.

\section{B. Baer $(\square)$}

ARC Centre of Excellence in Plant Energy Biology,

The University of Western Australia, MCS Building M316,

Crawley 6009, Australia

e-mail: bcbaer@cyllene.uwa.edu.au

B. Baer

Centre for Evolutionary Biology,

School of Animal Biology (MO92),

The University of Western Australia, Crawley 6009, Australia

S. P. A. den Boer · D. J. C. Kronauer · D. R. Nash ·

J. J. Boomsma

Centre for Social Evolution, Department of Biology,

University of Copenhagen, Universitetsparken 15,

2100 Copenhagen, Denmark

D. J. C. Kronauer

Museum of Comparative Zoology Labs, Harvard University,

26 Oxford Street, Cambridge, MA 02138, USA indicate that mature banded cat eyed snakes are able to enter and oviposit in large and well defended Atta colonies without being attacked by ant soldiers and that also newly hatched snakes manage to avoid ant attacks when they leaving their host colony. We speculate that $L$. annulata might use Atta and Acromyrmex leafcutter ant colonies as egg nurseries by some form of chemical insignificance, but more work is needed to understand the details of this interaction.

Keywords Social insects - Reproduction - Reptiles · Ant-vertebrate interactions

\section{Introduction}

Social insect colonies offer various opportunities for interaction with other species, but the nature of these associations varies greatly. Some are commensals, using waste products of their host colonies (Alford, 1975), but a large number are known to be parasites (Schmid-Hempel, 1995), predators (Vitt et al., 2007) or mutualists (Hölldobler and Wilson, 1990) that may present sophisticated co-evolutionary relationships with their hosts (Mueller, 2002). Relatively few of these associations are known to involve vertebrates (but see Scherba, 1965; Vitt et al., 2007), and most of these seem to be rather passive, for example, exploiting social insect nest structures as burrows or nesting cavities. Direct physical contact between the social insect hosts and these vertebrate intruders is normally avoided, and if it occurs the host workers express aggressive responses (Scherba, 1965). However, a special association seems to occur between some reptiles and social insect colonies as several observations of snake eggs in ant nests have been reported (Brandão and Vanzolini, 1985). 


\section{Methods and results}

During fieldwork in Gamboa, Republic of Panama (May 2007), we partially excavated several large (producing many sexuals) colonies of the leaf-cutting ant Atta colombica at the transition between a forest patch and grassland. In one of these colonies, located at $9^{\circ} 07^{\prime} 13^{\prime \prime}$ North and $79^{\circ} 41^{\prime} 42^{\prime \prime}$ West, about $60 \mathrm{~m}$ above sea level, we detected a total of five ellipsoid eggs $(\mathrm{ca} .2 \times 6 \mathrm{~cm})$ with a soft white shell. They were found in two clutches in neighboring fungus chambers about $1 \mathrm{~m}$ below the surface, containing two and three eggs, respectively. The eggs were found in the upper part of the fungus chambers. They were physically attached to each other and were completely covered by fungus garden material, with fungal hyphae still being attached to the eggs after they were taken out. We collected all five eggs, together with their fungus gardens and kept them under laboratory conditions in Panama at ambient humidity and temperature. Using a bright headlamp, we inspected the inside of the eggs and detected the presence of small embryos in all five eggs. After a week, we re-excavated the original host colony and re-sampled both fungus gardens and ants. We removed the earlier collected eggs from their original fungus garden and placed them on top of the freshly collected fungus garden material, but the ant workers ignored the eggs while they rebuilt their fungus garden and actively embedded the eggs in a similar way as originally observed. After this experiment we transferred the eggs to a plastic box, covered them with moist sand and kept them at $26^{\circ} \mathrm{C}$ and $60 \% \mathrm{rH}$. Two snakes eventually hatched and were identified as banded cat-eyed snakes Leptodeira annulata L. (see supplementary online material at http://www.ciber.science.uwa.edu.au/People/BorisBaer/ leafcutterants/snake.html).

\section{Discussion}

According to Vitt (1996), L. annulata is the most commonly encountered nocturnal snake in most areas of Amazonia. It is an arboreal snake of up to $66 \mathrm{~cm}$ in length that is active both on the ground and on vegetation, and specializes in catching frogs. The mean clutch size observed is 4.7 eggs, which is close to the 5 eggs that we detected during our excavations, suggesting that these eggs were laid by a single female.

We have excavated numerous colonies of leafcutter ant species in Panama since 1993 (usually in May/June), including Atta colombica, Atta sexdens, Atta cephalotes, Acromyrmex octospinosus and Acromyrmex echinatior, but have never encountered snake eggs before. Eggs of L. annulata have earlier been found in an unusually large colony of A. octospinosus in Venezuela (Brandão and
Vanzolini, 1985), so that our single observation adds to the evidence that $L$. annulata may use fungus gardens of large leafcutter ant colonies as egg nurseries. Further work is obviously needed to clarify whether this relationship is merely casual, as L. annulata has been reported to oviposit at many different sites, or whether this snake has adaptations that tend to predispose it to using fungus gardens when they are available. For example, more detailed information about the reproductive cycle of $L$. annulata would allow us to predict more accurately in what timeframe these snake eggs could be expected to be present in leafcutter ant fungus gardens.

Given that the previous observation by Brandão and Vanzolini (1985) concerned Acromyrmex host ants, it is intriguing that our present excavation concerns A. colombica, whose colonies are defended by soldiers who could easily cut the shells of snake eggs if they would recognize them as unwelcome intruders. This suggests that the eggs, the adult snakes that lay them and the newly hatched juveniles lack any smells that elicit aggression, so that they appear to biochemically insignificant (Lenoir et al., 2001). This suggests that investigating the surface chemistry of these snakes and their eggs may be of interest, because anti-recognition adaptations have been found or suggested for other snakes that prey on ants (Webb et al., 2000; Gehlbach et al., 1968).

From the snake's point of view, leafcutter ant fungus gardens may offer ideal oviposition sites, provided they can avoid aggression by their hosts. Fungus gardens offer temperature and humidity conditions (Bollazzi and Roces, 2002; Vaz-Ferreira et al., 1970) that may well be optimal for snake egg development (Brandão and Vanzolini, 1985). In addition, although the ant hosts do not actively defend the snake eggs, their embedding in fungus gardens must offer extremely good protection against predation relative to oviposition anywhere else.

Acknowledgments We thank Abdi Hedayat and the Smithsonian Tropical Research Institute in Panama for facilities and logistic support and the Autoridad Nacional de Ambiente (ANAM) for issuing collecting permits. Gunther Köhler helped with identifying the young snakes. This work was supported by grants from the Danish National Research Foundation to JJB and DRN and an Australian Research Council Queen Elizabeth II Fellowship to BB.

\section{References}

Alford D.V. 1975. Bumblebees. Davis-Poynter, London. 352 pp

Bollazzi M. and Roces E. 2002. Thermal preference for fungus culturing and brood location by workers of the thatching grasscutting ant Acromyrmex heyeri. Insect. Soc. 49: 153-157

Brandão C.R.F. and Vanzolini P.E. 1985. Notes on incubatory inquilinism between Squamata (Reptilia) and the neotropical fungus-growing ant genus Acromyrmex (Hymenoptera: Formicidae). Pap. Avul. Zool. 36: 31-36 
Gehlbach F.R., Watkins J.F. II and Reno H. 1968. Blind snake defensive behaviour elicited by ant attacks. Bioscience 18: 784-785

Hölldobler B. and Wilson E.O. 1990. The Ants. Springer Verlag, Berlin. $732 \mathrm{pp}$

Lenoir A., D'Ettorre P., Errard C. and Hefetz A. 2001. Chemical ecology and social parasitism in ants. Annu. Rev. Entomol. 46: 573-599

Mueller U.G. 2002. Ant versus fungus versus mutualism: Ant-cultivar conflict and the deconstruction of the attine ant-fungus symbiosis. Am. Nat. 160: 67-98

Scherba G. 1965. Observations on Microtus nesting in ant mounds. Psyche 72: 127-132

Schmid-Hempel P. 1995. Parasites and social insects. Apidologie 26: 255-271
Vaz-Ferreira R., de Zolessi L. C. and Achaval F. 1970. Oviposición y desarrollo de ofidios y lacertilios en hormigueros de Acromyrmex. Physis 29: 431-459

Vitt L.J. 1996. Ecological observations on the tropical Colubrid snake Leptodeira annulata. Herpet. Nat. Hist. 4: 69-76

Vitt L.J., Shepard D.B., Caldwell J.P., Vieira G.H.C., Franca F.G.R. and Colli G.R. 2007. Living with your food: geckos in termitaria of Cantao. J. Zool. 272: 321-328

Webb J.K., Shine R., Branch W.R. and Harlow P.S. 2000. Lifehistory strategies in basal snakes: reproduction and dietary habits of the African thread snake Leptotyphlops scutifrons (Serpentes: Leptotyphlopidae). J. Zool. Lond. 250: 321-327 